\title{
Análise do Uso Público do Parque Estadual do Monge, Lapa/PR
}

\author{
Mariana Meira Micaloski ${ }^{1}$, Fernanda Moura Fonseca Lucas $^{1}$, Letícia Helena Ribeiro da Cunha ${ }^{1}$, \\ Barbara Gabriele de Souza Nogueira ${ }^{1}$, Ronaldo Viana Soares ${ }^{1} \&$ Alexandre França Tetto ${ }^{1}$
}

Recebido em 12/08/2020 - Aceito em 17/11/2020 1 Universidade Federal do Paraná, Brasil. <micaloskimariana@gmail.com, fernanda-fonseca@hotmail.com, leticia.ufv@gmail.com,
barbaragsnogueira@gmail.com, rvsoares@ufpr.br, tetto@ufpr.br>.

\begin{abstract}
RESUMO - O uso público de uma unidade de conservação é caracterizado como a forma pela qual os visitantes utilizam essas áreas. As atividades provenientes do uso provocam efeitos positivos no âmbito socioeconômico; no entanto, sem mecanismos de controle e de monitoramento, podem proporcionar impactos negativos ao meio. Diante deste contexto, o objetivo do estudo foi realizar o levantamento de dados sobre a atual situação do uso público do Parque Estadual do Monge, localizado no município da Lapa, Paraná. A coleta de informações se deu por meio de questionário aplicado ao gestor da unidade. Os dados sobre a visitação, referentes aos anos de 2012 a 2016, foram obtidos por meio do Instituto de Água e Terra do Paraná. Observou-se nos resultados uma crescente taxa de visitação ao longo dos anos, porém não se têm dados mais específicos sobre o perfil desses visitantes $e$ a sua satisfação. Notou-se a necessidade de melhoria na infraestrutura e sinalização do Parque, bem como implementação dos subprogramas de uso público previstos no plano de manejo. Neste sentido, recomenda-se atenção aos parâmetros para gestão da unidade, de modo que a visitação possa ser potencializada estrategicamente, estimulando a participação social, com vistas a garantir os objetivos de criação do Parque Estadual do Monge.
\end{abstract}

Palavras-chave: Áreas naturais protegidas; ecoturismo; lazer.

\section{Analysis of the Public Use of the Parque Estadual do Monge, Lapa/PR}

ABSTRACT - The public use of a conservation unit is characterized as how visitors use these areas. The activities resulting from the use of provoking positive effects in the socioeconomic sphere; however, without control and monitoring mechanisms they can provide negative impacts to the environment. Given this context, the objective of the study was to conduct a data survey on the current situation of public use of the Monge State Park, located in the municipality of Lapa, Paraná. The collection of information was done using a questionnaire to the unit manager. The data on visitation, for the years 2012 to 2016, were obtained through the Instituto de Água e Terra do Paraná. The results showed an increasing visitation rate over the years, but no more specific data on the profile of these visitors and their satisfaction was available. There was a need to improve the park's infrastructure and signage, as well as to implement the sub-programs for public use foreseen in the management plan. In this sense, attention to these parameters is recommended for the management of the unit, so that visitation can be enhanced strategically, stimulating social participation, to guarantee the objectives of creating the Monge State Park.

Keywords: Natural protected areas; ecotourism; leisure.

\section{Análisis del Uso Público del Parque Estadual do Monge, Lapa/PR}

RESUMEN - El uso público de una unidad de conservación se caracteriza por la forma en que los visitantes utilizan esas zonas. Las actividades resultantes del uso tienen efectos socioeconómicos positivos, sin embargo, sin mecanismos de control y vigilancia pueden tener efectos negativos en el medio ambiente. En este contexto, el objetivo del estudio fue realizar una encuesta de datos sobre la situación actual del uso público del Parque Estatal de Monge, ubicado en el municipio de Lapa, Paraná. La recopilación de información se realizó mediante un cuestionario dirigido al gerente de la unidad. Los datos sobre las visitas, correspondientes a los años 2012 a 2016, se obtuvieron por conducto del Instituto del Agua y la Tierra de Paraná. Los resultados mostraron un aumento de la tasa 
de visitas a lo largo de los años, pero no se disponía de datos más específicos sobre el perfil de estos visitantes y su satisfacción. Era necesario mejorar la infraestructura y la señalización del parque, así como ejecutar los subprogramas de uso público previstos en el plan de ordenación. En este sentido, se recomienda prestar atención a estos parámetros para la gestión de la unidad, de manera que se pueda mejorar estratégicamente la visita, estimulando la participación social, con el fin de garantizar los objetivos de la creación del Parque Estatal de Monge.

Palabras clave: Áreas naturales protegidas; ecoturismo; recreación.

\section{Introdução}

Em 2000 foi instituído no Brasil o Sistema Nacional de Unidades de Conservação da Natureza (SNUC), por meio da Lei $n^{\circ} 9.985$, que estabelece os critérios e normas para criação, implantação e gestão das unidades de conservação (UCs). Esse sistema divide as UCs em dois grupos: o de proteção integral, que objetiva a preservação da natureza, permitindo apenas o uso indireto de seus recursos; e o de uso sustentável, que visa à conservação da natureza e permite o uso sustentável de seus recursos naturais (Brasil, 2000). Esses grupos são divididos em categorias e permitem o desenvolvimento de atividades de uso público.

De maneira geral, o termo "uso público" caracteriza a forma de utilização das UCs pelos visitantes, podendo se dar por meio de atividades recreativas, educacionais, de pesquisa e de ecoturismo, considerado uma estratégia de valorização social, ambiental, econômica $e$ cultural das áreas protegidas (Marques \& Rocha, 2019). Segundo o levantamento realizado por Souza et al. (2017), as atividades de visitação em UCs são importantes ferramentas para economia brasileira, com a geração de empregos diretos $e$ indiretos, promovendo o desenvolvimento local e movimentando a indústria de turismo nacional.

Conciliar as atividades de uso público e o objetivo das UCs é um dos principais desafios de seus gestores (Reis \& Queiroz, 2017). Acredita-se que a interação da população com o meio aumente o interesse em contribuir com a conservação (Bellinassi et al., 2011). No entanto, embora surtam efeitos positivos principalmente no âmbito socioeconômico -, o desenvolvimento dessas atividades também pode proporcionar impactos negativos, havendo a necessidade de estabelecer mecanismos de controle e monitoramento (Moaes \& Lignon, 2012). O bom planejamento para as atividades do uso público permite o desenvolvimento de um ecoturismo sustentável, capaz de cooperar com a sociobiodiversidade existente (Andrade et al., 2020).

Quando isso não ocorre, surgem riscos $e$ ameaças, que podem resultar em efeitos críticos aos meios físico e biótico, como a perda de cobertura vegetal, introdução de espécies invasoras e erosão do solo, promovendo, de maneira geral, a degradação dos recursos, que em muitos casos atingem situações irreversíveis (Marques \& Rocha, 2019). Além disso, a falta de infraestrutura, como placas de sinalização $e$ espaços adequados para apreciação da paisagem, resulta em atividades errôneas na UC por parte dos usuários visitantes, como por exemplo acampamento em locais inapropriados e descartes incorretos de lixos, pondo em risco a segurança pública e ambiental (Marques \& Rocha, 2019). Neste sentido, há necessidade de investimentos que garantam a conservação dos serviços naturais e que promovam a qualidade nas experiências dos visitantes (Souza et al., 2017).

Deste modo, reconhece-se a necessidade de estudos e levantamentos de dados sobre a visitação como importantes ferramentas para construção e implantação do plano de uso público da unidade (Andrade et al., 2020). Diante desta perspectiva, o presente estudo teve como objetivo realizar um levantamento sobre a taxa de visitação $e$ a infraestrutura disponibilizada em um parque estadual do Paraná, com a finalidade de gerar dados que possam subsidiar tomadas de decisão para o manejo da visitação, garantindo que a unidade proporcione entretenimento sem se desvincular de sua função ecológica.

\section{Material e Métodos}

\section{Caracterização da área de estudo}

O Parque Estadual do Monge (PEM) está localizado no município da Lapa (2546'11" de latitude sul e 49²' $57^{\prime \prime}$ de longitude oeste), 
onde se encontra uma das cidades mais antigas do estado do Paraná, localizada a $72,1 \mathrm{~km}$ de Curitiba (Figura 1), com uma área territorial de $2.098,442 \mathrm{~km}^{2}$ e uma população de 48.163 habitantes (IPARDES, 2020).

A cidade da Lapa situa-se em uma área conhecida como "Rota do Pinhão", de acordo com a Secretaria do Desenvolvimento Sustentável e do Turismo, o que é um atrativo para os turistas conhecerem o Parque e a cidade, que tem imóveis tombados pelo Patrimônio Histórico e Artístico Natural (SEDEST, 2020).
O PEM é uma unidade de conservação de proteção integral, criada a partir da Lei Estadual $\mathrm{n}^{\circ} 4.170$, de 22 de fevereiro de 1960, tendo como unidade gestora o Instituto Água e Terra (IAT), antigo Instituto Ambiental do Paraná (IAP), órgão ambiental do estado. O Parque possui uma área de 297,83ha, localizado a 3km de distância do centro da cidade, em uma região de transição entre o Primeiro e o Segundo Planalto. Possui uma característica vegetacional campestre, denominada estepe gramíneo-lenhosa, com características de floresta ombrófila mista. A unidade recebeu este

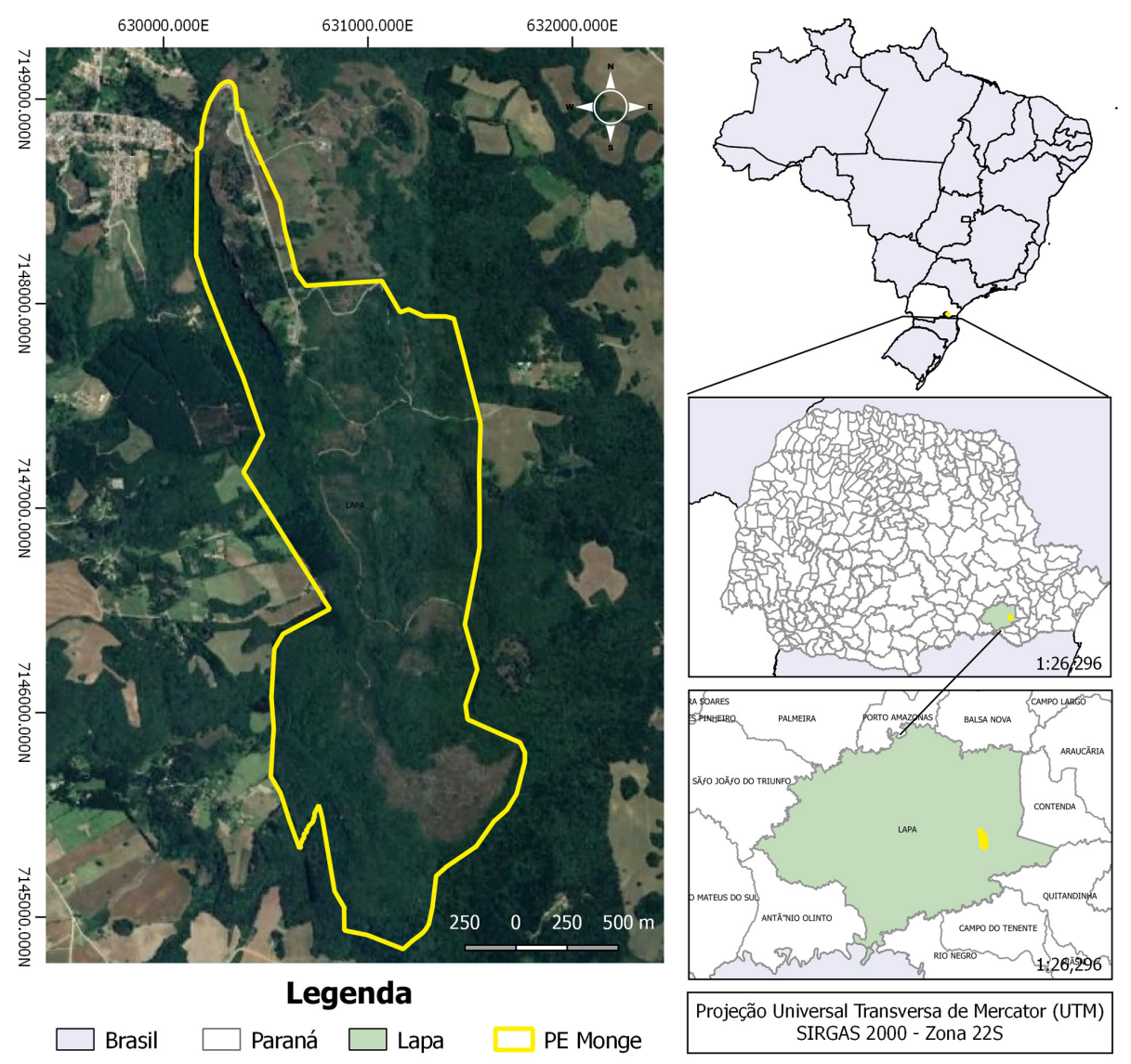

Figura 1 - Localização do Parque Estadual do Monge, município da Lapa/PR. Adaptado de IAP (2002).

nome devido ao monge João Maria d'Agostini, que, durante os anos de 1847 a 1855, abrigou-se em uma gruta dentro da área (IAP, 2002).

O plano de manejo do Parque é datado de dezembro de 2002, e os programas de manejo previstos no documento estão estruturados em cinco linhas, sendo: conhecimento, manejo do ambiente, uso público, operacionalização $e$ integração com a área de influência. O programa de uso público do Parque Estadual do Monge "diz respeito às ações e atividades necessárias para a recepção e atendimento ao visitante" (IAP, 2002), que têm como objetivo a ordenação, a orientação e o direcionamento do uso do Parque pelo público, sem que haja alterações significativas dos recursos naturais. Segundo o mesmo autor, para atingimento desses objetivos, o programa é composto por três subprogramas: recreação e interpretação ambiental, educação ambiental e concessões. 
Segundo o zoneamento do Parque (Figura 2), as zonas de uso intensivo e extensivo são as áreas destinadas para visitação e correspondem a 2,4\% da área total do Parque (Tabela 1) (IAP, 2002).

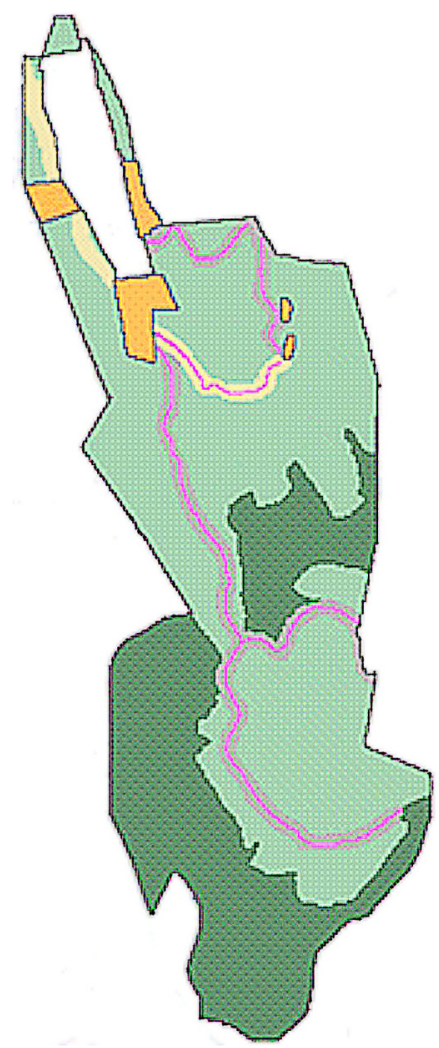

\section{Zoneamento}

Zona Primitiva

Zona de Uso Extensivo

Zona de Uso Intensivo

Zona de Recuperação

Zona de Uso Especial

Zona de Uso Confitante

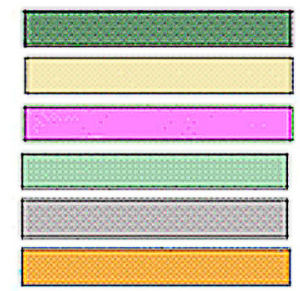

Figura 2 - Zoneamento do Parque Estadual do Monge/PR. Fonte: adaptado de IAP (2002).

Tabela 1 - Distribuição das áreas no zoneamento do Parque Estadual do Monge/PR.

\begin{tabular}{|c|c|c|}
\hline Zonas & Áreas (ha) & \% da área do Parque \\
\hline Zona Primitiva & 98,14 & 32,08 \\
\hline Zona de Uso Extensivo & 6,8 & 2,22 \\
\hline Zona de Uso Intensivo & 0,54 & 0,18 \\
\hline Zona de Recuperação & 165,23 & 54,02 \\
\hline Zona de Uso Especial & 26,08 & 2,98 \\
\hline Zona de Uso Conflitante & 9,08 & $\mathbf{1 0 0}$ \\
\hline
\end{tabular}

* Total inclui 8,04ha a serem incorporados à área do Parque na Zona de Recuperação. Fonte: IAP (2002)

A área de visitação do Parque conta com a gruta do Monge, que recebe visitantes com objetivo religioso, além de trilhas (turismo de aventura) e o mirante (SEDEST, 2020). 
O subprograma de recreação e interpretação ambiental "visa proporcionar atividades de recreação $e$ interpretação em ambiente natural, compatíveis com as características $e$ objetivos da unidade, fornecendo ao visitante informações básicas sobre os aspectos naturais da área" (IAP, 2002). O subprograma de educação ambiental "trata da organização de atividades que oportunizem ao visitante conhecimentos $e$ valores do patrimônio natural e cultural da área, interpretando seus recursos" (IAP, 2002); e o subprograma de concessões visa à criação de concessões, como uma forma de estimular a iniciativa privada para atendimento das necessidades dos visitantes dentro da UC (IAP, 2002).

\section{Obtenção e análise de dados}

A metodologia utilizada para o diagnóstico do uso público do PEM foi a aplicação de questionário ao gestor da unidade, além de visita in loco para caracterizar as infraestruturas e os atrativos presentes. O questionário baseou-se no trabalho de Zimmermann (2006), que estudou a gestão da visitação nos parques nacionais do Brasil.

O questionário foi adaptado para a realidade do PEM, tomando como base o que está proposto no plano de manejo, sendo dividido em oito eixos: informações iniciais sobre a visitação, infraestrutura, recursos financeiros, funcionários, estratégias de gestão, gestão participativa, informações gerais e programa de uso público. Os dados sobre a visitação do Parque Estadual do Monge, de 2012 a 2016, foram obtidos no site do IAT, organizados em gráficos por meio do software Excel e submetidos à estatística descritiva para os valores mensais no software BioEstat 5.0 (Ayres et al., 2007).

\section{Resultados e Discussão}

No período da pesquisa, apenas a visitação $e$ a caminhada pelas trilhas eram as atividades recreativas previstas no plano de manejo oferecidas ao público. Por meio dos dados de controle de visitantes existentes na entrada, notou-se que o PEM apresentou um crescente aumento na visitação, com o registro, no ano de 2012, de 15.394 visitantes e, em 2016, de 77.400, mostrando seu potencial de visitação e de uso público (Figura 3). Esse aumento no número de visitantes também está relacionado ao fato de que, durante os anos de 2009 a 2011, o Parque ficou fechado para revitalização, sendo reaberto para visitação em 2012, sem comunicado oficial à população do município (Micaloski et al., 2018).

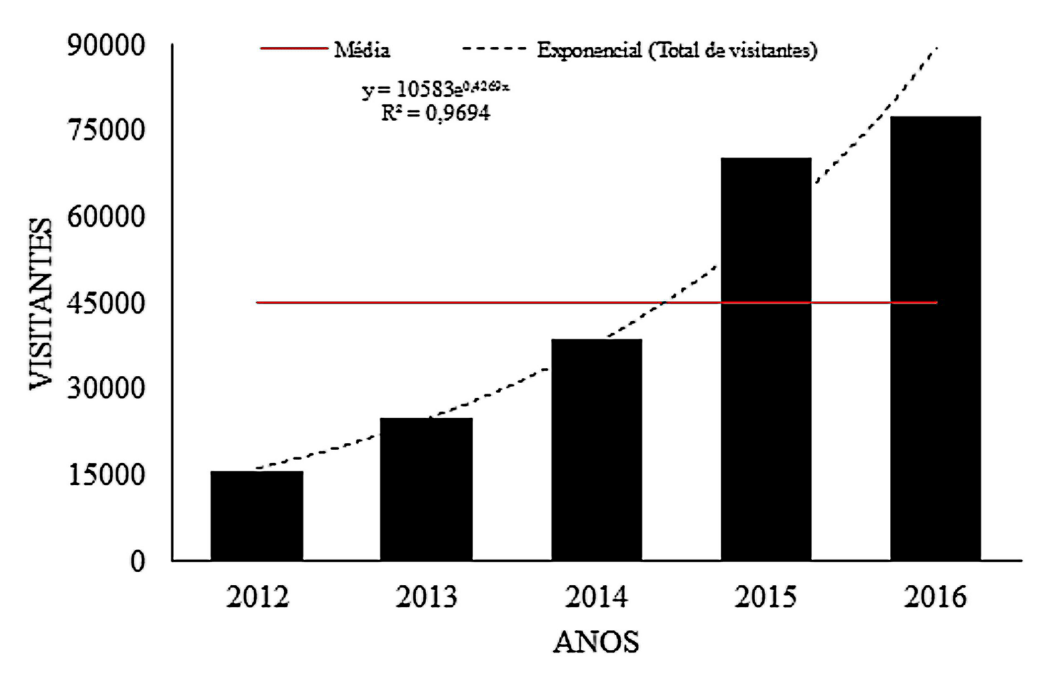

Figura 3 - Total da visitação atendida pelo Parque Estadual do Monge/PR, nos anos de 2012 a 2016.

Conforme o total de visitantes mensais obtidos de 2012 a 2016 (Figura 4), apenas os meses de fevereiro, março, maio e agosto apresentaram-se abaixo da média. A maior demanda foi observada no mês de novembro (23.757 visitantes), e a menor no mês de agosto (13.017 visitantes); 
no entanto, obteve-se um baixo coeficiente de variação $(\mathrm{CV}=14,69 \%)$ entre a taxa de visitação mensal, o que indica que, embora haja alguns picos no fluxo de visitação, não há sazonalidade da demanda ao longo do ano. Embora não seja realizada a caracterização do perfil dos visitantes, acredita-se que a maioria sejam os próprios lapeanos, devido à proximidade da unidade com a cidade da Lapa, e visitantes oriundos da capital do estado, também devido à proximidade.

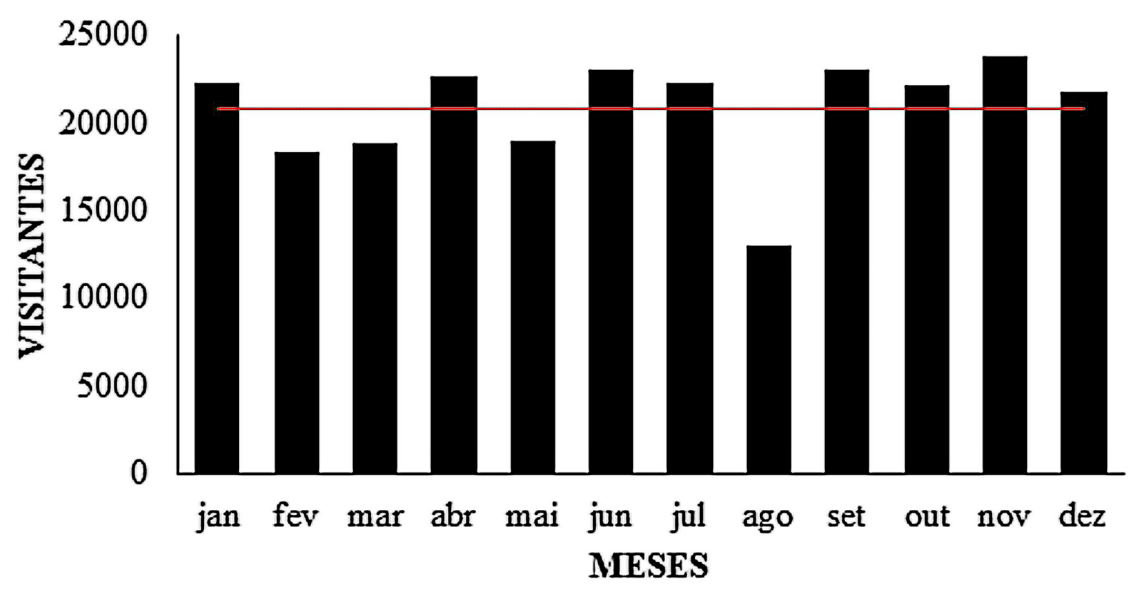

Total de visitantes — Média

Figura 4 - Total de visitantes atendidos por mês pelo Parque Estadual do Monge/PR, nos anos de 2012 a 2016.

Apesar de não haver sazonalidade, foi observada a presença de fluxos acima da média para alguns meses. O número de visitantes em abril pode ser explicado pela quantidade de feriados, datas que aumentam a movimentação, sendo a alta demanda por ecoturismo durante a Semana Santa também observada para o Parque Estadual do Ibitipoca/MG (Ladeira et al., 2007). O número de visitantes se intensifica no mês de setembro, principalmente pelo início da primavera, estendendo-se até janeiro - período de alta temporada para várias localidades devido às férias. Considera-se este último motivo como a razão para o fluxo também acima da média nos meses de junho e julho.

O Parque Estadual do Monge possui centro de visitantes, banheiros, auditório e centro de apoio, utilizado como depósito e almoxarifado do setor administrativo (Figura 5), o que pode ser considerado um ponto forte da área. Porém essas estruturas, com exceção dos banheiros, encontramse fechadas devido à necessidade de revitalização. Também se observou que as estruturas existentes no Parque não permitem acessibilidade a todos; instalações com acessibilidade proporcionam melhor atendimento, garantem o bem-estar, diversificam $e$ incluem usuários. Logo, se faz necessária a inserção de adaptações, tendo em vista que esses ambientes, além de contribuírem com a conservação da biodiversidade local, também são espaços para lazer e entretenimento da população (Lima et al., 2020). Estruturas fechadas $e$ sem acessibilidade dificultam o atingimento dos objetivos da unidade, tendo em vista que impedem a comunicação e a ligação da área com a comunidade. Instalações de acessibilidade proporcionam melhor atendimento, garantem o bem-estar, diversificam e incluem usuários.

Com relação aos recursos financeiros do Parque, a visitação é gratuita, não havendo a cobrança de ingressos para pessoas físicas ou jurídicas. Apesar de atualmente não existir essa cobrança, a possibilidade já vem sendo estudada para futura aplicação, sendo que a origem dos recursos financeiros utilizados para a gestão de manutenção da unidade é proveniente do IAT e de medidas compensatórias.

O Parque possui um quadro de funcionários constituído por quatro integrantes: o gestor e os demais atuantes em atividades operacionais, 


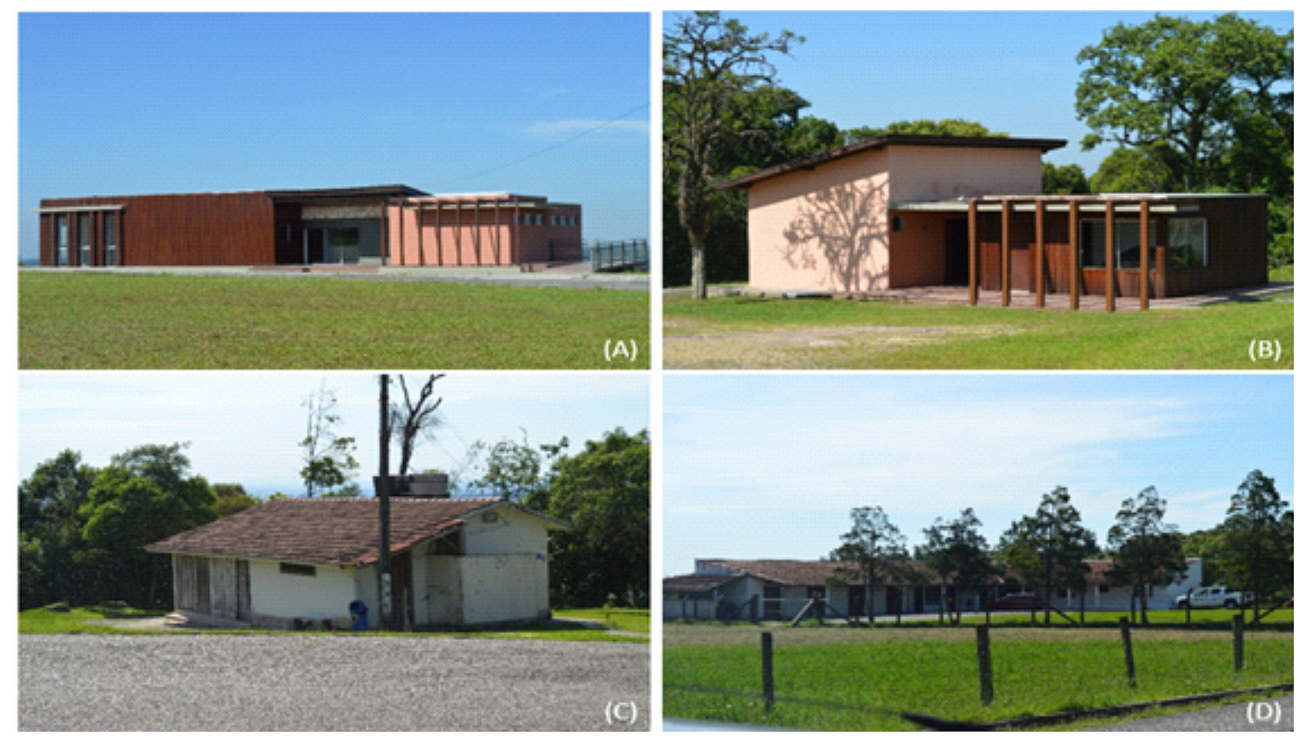

Figura 5 - Infraestrutura presente no Parque Estadual do Monge/PR: centro de visitantes (A); centro de apoio (B); banheiros (C); sede provisória (D). Fonte: os autores (2020).

como manutenção e fiscalização. Nenhum desses funcionários trabalha especificamente com uso público; assim, todas as atividades recreativas realizadas no Parque são feitas de maneira autônoma pelos visitantes, sem a presença de guarda-parques ou monitores disponíveis para orientação, nem atividades de interpretação ambiental para enriquecer a visita. De acordo com o gestor, para um melhor manejo do PEM $e$ atendimento ao público, seria necessário, no mínimo, o dobro de funcionários existentes. Desta maneira, poderia haver uma fiscalização mais adequada, e os funcionários poderiam ser capacitados para atendimento ao público.

Ao analisar a gestão de seis parques estaduais do Paraná - Pico do Marumbi, Vila Velha, Guartelá, Cerrado, Mata dos Godoy e Rio Guarani -, Nogueira (2017) relata que nos parques estudados não há um quadro de funcionários suficiente para uma gestão adequada. Esse problema não é exclusivo dos parques do Paraná, segundo o estudo realizado por Zimmermann (2006). Nos Parques Nacionais da Serra dos Órgãos, do Caparaó e da Chapada dos Veadeiros, também se observou a falta de recursos humanos, fator que, segundo a autora, dificulta a gestão da unidade, já que a falta de prestadores de serviço faz com que o recurso seja alocado apenas para a atitude de fiscalizar a ação humana, ao invés de instruir e estimular o cuidado com a natureza.
A falta de recursos, sejam eles financeiros ou humanos, é uma ameaça para a gestão das áreas protegidas e, portanto, para sua efetiva conservação. As consequências dessa ameaça podem ser observadas, por exemplo, no Parque Nacional da Serra da Capivara (PNSC). O Parque, localizado no Piauí e criado em 1979, foi incluído pela Unesco na lista do Patrimônio Mundial em 1991 devido à importância dos registros rupestres do local $e$, atualmente, pela falta de recursos financeiros para sua gestão e manutenção, está sofrendo pressões para seu fechamento (Tokarnia, 2017).

A visitação em UCs é uma forma de aproximar a sociedade das áreas naturais protegidas, despertando o interesse da sociedade sobre a conservação da natureza (MMA, 2007). Para Takahashi (2004), a divulgação das características e qualidades das áreas protegidas, através dos meios de comunicação, fazem com que a sociedade se sinta atraída pela diversidade das áreas, despertando o interesse em conservar tais ambientes. No Parque do Monge, a visitação é permitida, porém não há meio oficial de incentivo a essa prática ou qualquer programa para visitação de pessoas da comunidade do entorno. Apesar de o contato do homem com o ambiente natural ser importante, a unidade sofre alguns impactos negativos provenientes da visitação. De acordo com o gestor do Parque, os principais problemas 
são a questão dos resíduos deixados na área e a pichação nas formações rochosas.

O uso público deve ser bem planejado para que seja possível harmonizar a conservação $e$ a recreação. Para isso, é preciso realizar estudos sobre as condições ambientais do local e sobre as características dos visitantes (Takahashi, 2004). Em relação ao PEM, não há pesquisas sobre o nível de satisfação ou sobre o perfil dos visitantes da unidade, o que impede um conhecimento sobre a demanda de seu uso público e compromete o bom funcionamento do programa, pois essas informações influenciam nas decisões de manejo da visitação. Segundo Roggenbuck \& Lucas (1987), conhecer o perfil dos visitantes auxilia a gestão das áreas por meio da compreensão do comportamento do público, possibilitando uma melhoria na qualidade da experiência dos visitantes. Para Takahashi (1998), as informações sobre os usuários e suas características são pré-requisitos na preparação de planos de manejo concretos.

Segundo o plano de manejo do PEM, o subprograma de recreação e interpretação ambiental prevê a capacitação de pessoal para o devido manejo das trilhas, além de disponibilidade de equipamentos e ferramentas para a sua manutenção. No entanto, não houve atividades que possibilitassem a capacitação dos funcionários. Além disso, esse subprograma também prevê a recuperação, reestruturação e implantação de trilhas. Entretanto, durante a entrevista com o gestor do Parque e visita in loco, se observou que não foram implementadas novas trilhas. Para as três trilhas existentes - uma delas, a Trilha das Pedreiras, que dava acesso à piscina de pedra, foi interditada devido à baixa qualidade da água. As outras duas, a Gruta do Monge e a Pedra Partida, correspondem a um único trajeto que dá acesso ao local onde o monge João Maria d'Agostini se abrigava. Essa trilha possui um trajeto curto, com uma duração de 30 minutos em média, e passou por um processo de revitalização entre os anos de 2009 e 2011.

Em relação ao subprograma de educação ambiental, três projetos foram indicados no plano de manejo: A Lapa vai ao Parque, Projeto de Educação Ambiental e Projeto Mínimo Impacto. O projeto A Lapa vai ao Parque propõe atividades de educação ambiental voltadas exclusivamente à população lapeana, com o objetivo de aumentar o laço histórico-afetivo com o PEM. As atividades propostas neste projeto contemplam visitas orientadas para a população local, visando à compreensão da importância do Parque, tanto no contexto natural, quanto cultural e socioeconômico, além do desenvolvimento de um programa de educação ambiental para as escolas da Lapa.

O Projeto de Educação Ambiental prevê o desenvolvimento de atividades formais, aquelas desenvolvidas dentro de uma instituição de ensino, $e$ informais, que são atividades relacionadas a outras maneiras de educação, como por exemplo, por guias de turismo. Por fim, o Projeto Mínimo Impacto tem como objetivo informar aos visitantes sobre as técnicas de mínimo impacto, garantindo a proteção dos recursos naturais da área, por meio de materiais, oficinas e exposições que informem sobre essas técnicas. Entretanto, conforme entrevista realizada com o gestor do PEM, nenhuma atividade de educação ambiental está sendo desenvolvida, assim como nenhum material institucional sobre a UC foi elaborado, e não há parcerias entre o Parque e as escolas da região. Portanto, somente o Projeto Mínimo Impacto foi implementado. Neste sentido, os funcionários foram instruídos em relação às normas $e$ aos procedimentos de visitação e segurança para que possam repassar ao público; porém, tais normas $e$ procedimentos são informados aos visitantes apenas quando solicitados.

Nos parques analisados por Nogueira (2017), observou-se a realização de atividades educativas nas unidades, sendo atividades de sensibilização sobre os resíduos nos campings do Parque Estadual Pico do Marumbi; atividades espontâneas realizadas por escolas particulares ou públicas; cursos técnicos e universidades, como no caso dos Parques de Vila Velha e do Guartelá; ou atividades educativas agendadas, como no caso do Parque Estadual Mata dos Godoy.

A educação ambiental (EA) ajuda a promover a consolidação do uso público em unidades de conservação. Este instrumento pode ser utilizado como forma de inserção social, contribuindo para qualificar a participação $e$ a valorização do espaço público. Queiroz \& Vallejo (2017) ressaltam que a EA dever partir da perspectiva de compreensão da realidade, inserindo problemas para gerar mais criticidade $e$ incentivo às proposições que poderiam melhorar o planejamento do uso público.

O subprograma de concessões visa a permitir o uso da área por particulares, estimulando a iniciativa privada para atendimento 
das necessidades dos visitantes dentro da UC. Neste subprograma, foram propostos os projetos: Concessões, Piscina de Pedra e Condutores Locais. Conforme entrevista com o gestor, nenhum destes projetos foi efetivado. Apesar disso, o Parque Estadual do Monge faz parte de um projeto do governo do estado que averigua o processo de concessão total ou parcial de áreas designadas ao uso público em unidades de conservação estaduais.

No estado do Paraná, o processo de concessão foi aprovado por meio da Lei $\mathrm{n}^{\circ}$ 19.913/2019 e, dentre as unidades de conservação que estão sendo estudadas para a permissão, o Parque Estadual do Monge está entre os três primeiros. Vale ressaltar que a referida Lei coloca a obrigatoriedade de atualização do plano de manejo atualizado, assim como de um conselho gestor estabelecido e atuante.

O Decreto $^{\circ} 4.340$, de 22 de agosto de 2002 , que regulamenta o SNUC, prevê a possibilidade de exploração de bens e serviços dentro das unidades de conservação, desde que atendam aos objetivos estabelecidos para cada categoria e com decisão do órgão gestor. Os serviços de apoio à visitação consistem em alternativas que vêm sendo estudadas no nível federal, com destaque para os Parques Nacionais do Iguaçu, de Fernando de Noronha, da Tijuca e da Serra dos Órgãos, por intermédio de concessões, autorizações e permissões (Melo, 2012).

Reis e Queiroz (2017) discorrem sobre o tema para as unidades de conservação no estado de São Paulo, ressaltando a complexidade do assunto $e$ a necessidade de estimular o debate $e$ a elaboração de pesquisas para que essas áreas sejam utilizadas como espaços democráticos na conservação da biodiversidade e uso público. $\mathrm{O}$ estudo relata que São Paulo possui 25 áreas que autorizam a modalidade de permissões, assim como salientam a precarização dos serviços do estado. A implementação de uma unidade de conservação é um processo lento e gradual, passando obrigatoriamente pela compreensão dos atores sociais presentes no território. Além disso, cabe lembrar que essas áreas estão em constante processo de modificação, inclusive no modo de se relacionar com o espaço (Garcia et al., 2018). É neste sentido que a visitação pode ser potencializada de forma estratégica, no intuito de garantir o alcance dos objetivos de criação do Parque Estadual do Monge.
A esfera de gestão estadual possui dificuldades no correto planejamento e na implementação do uso público. Assim, encontrar mecanismos para o monitoramento da visitação por meio de parcerias com instituições de ensino e governamentais de nível municipal, além da implantação de programas de voluntariado, podem ser alternativas para minimizar os desafios e potencializar a efetividade de gestão dessas áreas.

\section{Conclusões}

O Parque Estadual do Monge é uma unidade de conservação com potencial de uso público demonstrado, principalmente, com o crescente aumento no número de visitantes ao longo dos anos. O levantamento realizado por este estudo apontou lacunas na implementação e no manejo da unidade devido, principalmente, à falta de recursos financeiros e humanos.

O plano de manejo do Parque está desatualizado, e seu programa de uso público, apesar de promissor, não foi implantado. Sendo assim, como o IAT segue as normas e diretrizes propostas pela legislação federal, sugere-se que o plano de manejo do Parque seja atualizado conforme o novo roteiro metodológico implementado pelo ICMBio em 2018, intitulado Roteiro Metodológico para Elaboração $e$ Revisão de Planos de Manejo das Unidades de Conservação Federais.

Também se recomenda, urgentemente, a elaboração de pesquisa básica para dados mais específicos sobre os visitantes da área, como, por exemplo o perfil, a percepção e a experiência dos visitantes, o que colaboraria para o direcionamento de uma gestão mais eficiente e condizente com a realidade.

\section{Referências}

Ayres M, Ayres-Junior M, Dayres D \& Santos A. Bioestat 5.0: aplicações estatísticas nas áreas de ciências biológicas e médicas. Belém, PA: Sociedade Civil Mamirauá. Brasília: CNPq, 2007. 364p.

Andrade TC, Souza TVSB \& Cunha AA. Estruturação do rol de oportunidades de visitação no Parque Nacional da Chapada dos Veadeiros (GO). Revista Brasileira de Ecoturismo, 13(2): 365-392, 2020. 
Bellinassi S, Pavão AC \& Cardoso-Leite E. Gestão e uso público de unidades de conservação: um olhar sobre os desafios e possibilidades. Revista Brasileira de Ecoturismo, 4(2): 274-293, 2011.

Brasil. 2000. Lei $n^{\circ}$ 9.985, de 18 de julho de 2000. Institui o Sistema Nacional de Unidades de Conservação da Natureza e dá outras providências. Diário Oficial da União. Disponível em: <http:/www.planalto.gov.br/ ccivil_03/leis/19985.htm >. Acesso em: 02/06/2020.

Brasil. 2002. Decreto n. 4.340, de 22 de agosto de 2002. Regulamenta artigos da Lei n. 9.985, de 18 de julho de 2000, que dispõe sobre o Sistema Nacional de Unidades de Conservação, e dá outras providências. Diário Oficial da União. Disponível em: <http://www. mma.gov.br/port/conama/legiabre.cfm?codlegi $=374>$. Acesso em: 21/10/2020.

Garcia LM, Moreira JC \& Burns R. Conceitos geográficos na gestão de unidades de conservação brasileiras. Geographia, 20(48): 53-62, 2018. <https:// doi.org/10.22409/GEOgraphia2018.v20i42.a13832>.

IAP (Instituto Ambiental do Paraná). Plano de manejo do Parque Estadual do Monge. Curitiba, dezembro de 2002.

IPARDES (Instituto Paranaense de Desenvolvimento Econômico e Social). Caderno estatístico município de Lapa. Curitiba, julho de 2020.

Ladeira AS, Ribeiro GA, Dias HCT, Schaefer CEGR, Fernandes Filho E \& Oliveira Filho AT. O perfil dos visitantes do Parque Estadual do Ibitipoca (PEIb), Lima Duarte, MG. Rev. Árvore, 31(6): 1091-1098, 2007.

Lima ABL, Melo IBN \& Gimenes-Minasse MHSG. Acessibilidade do Parque Natural Municipal Victório Siquierolli (Uberlândia/MG) para visitação de pessoas com deficiências física, auditiva e visual. Caderno Virtual de Turismo, v. 19, n. 3, 2020. < http://dx.doi. org/10.18472/cvt.19n3.2019.1574>.

Marques F \& Rocha MB. Impactos do uso público em unidades de conservação: produção científica no Rio de Janeiro, Research, Society and Development, 8(3): 26, 2019.

Melo AL. A institucionalização do uso público em ambiente governamental: uma análise frente ao desafio moderno de maximizar os resultados da conservação. In: VII Congresso Brasileiro de Unidades de Conservação. Disponível em: <https://issuu.com/adrianomelo/docs/ artigo_adriano_cbuc_2012>. Acesso em: 21/10/2020.

Micaloski MM, Soares RV \& Tetto AF. Percepção ambiental da população da cidade da Lapa - PR em relação ao Parque Estadual do Monge. Geografia (Londrina), 27(2): 73-86, 2018.
MMA (Ministério do Meio Ambiente). Unidades de conservação do Brasil. Brasília: Ministério do Meio Ambiente, 2007.

Moaes HMT \& Lignon MC. Caracterizando os visitantes do Parque Estadual da Ilha do Cardoso (SP): subsídio para o planejamento de atividades turísticaeducacional em áreas de manguezal. Revista Brasileira de Ecoturismo, 5(3): 666-683, 2012.

Nogueira BGS. 2017. A gestão da visitação em seis unidades de conservação no estado do Paraná. Dissertação (Mestrado em Engenharia Florestal) Setor de Ciências Agrárias, Universidade Federal do Paraná. 108p.

Paraná. Lei no 19.913, de 30 de agosto de 2019. Autoriza o Poder Executivo a conceder a exploração do uso, total ou parcial, de áreas destinadas ao uso público nas unidades de conservação, no âmbito do estado do Paraná. Disponível em: <http://portal. assembleia.pr.leg.br/modules/mod_legislativo_arquivo/ mod_legislativo_arquivo.php?leiCod $=51887 \&$ tipo $=\mathrm{L}$ \&tpleiei $=0$ > . Acesso em: 10/07/2020.

Queiroz ED \& Vallejo LR. Uso Público em Unidades de Conservação: entre o ideal e o real. Revista Eletrônica Uso Público em Unidades de Conservação. Universidade Federal Fluminense. 5(9): 1-15, 2017.

Reis AF \& Queiroz OTMM. Visitação no Parque Estadual da Cantareira (PEC): reflexões sobre o uso recreativo de uma Unidade de Conservação (UC). Revista de Turismo Contemporâneo, 5(1): 42-60, 2017.

Reis AF \& Queiroz OTMM. Concessões nas Unidades de Conservação do Estado de São Paulo: reflexões, oportunidades e desafios. Revista Brasileira de Ecoturismo (RBEcotur), 10(2): 65-72, 2017.

Roggenbuck JW \& Lucas RC. Wilderness use and user characteristics: a state-of-knowledge review. USDA; Forest Service, Fort Collins, 1987. (General Technical Report INT).

SEDEST (Secretaria do Desenvolvimento Sustentável e doTurismo).Disponívelem: < http://www.turismo.pr.gov. $\mathrm{br} / \mathrm{modules} /$ conteudo/conteudo.php?conteudo $=946>$. Acesso em: 28/07/2020.

Souza TVSB, Thapa B, Rodrigues CGO \& Imori D. Contribuições do turismo em unidades de conservação para a economia brasileira - efeitos dos gastos dos visitantes em 2015. ICMBio, 2017.

Takahashi LY. 1998. Caracterização dos visitantes, suas preferências e percepções e avaliação dos impactos da visitação pública em duas unidades de conservação do estado do Paraná. Tese (Doutorado em Engenharia Florestal) - Setor de Ciências Agrárias, Universidade Federal do Paraná. 144p. 
Takahashi LY. Uso público em unidades de conservação. Cadernos de Conservação, 30(4): 570-580, 2004.

Tokarnia M. Falta de recursos ameaça Parque Nacional da Serra da Capivara. Disponível em: <http:// agenciabrasil.ebc.com.br/politica/noticia/2016-05/ falta-de-recursos-ameaca-parque-nacional-da-serracapivara>. Acesso em: 04/04/2017.
Zimmermann A. 2006. Visitação nos parques nacionais brasileiros: um estudo à luz das experiências do Equador e da Argentina. Dissertação (Mestrado em Desenvolvimento Sustentável) - Centro de Desenvolvimento Sustentável, Universidade de Brasília, Brasília. 279p.

Biodiversidade Brasileira - BioBrasil.

Fluxo Contínuo

n. 1,2021

http://www.icmbio.gov.br/revistaeletronica/index.php/BioBR

Biodiversidade Brasileira é uma publicação eletrônica científica do Instituto Chico Mendes de

Conservação da Biodiversidade (ICMBio) que tem como objetivo fomentar a discussão e a disseminação de experiências em conservação e manejo, com foco em unidades de conservação $e$ espécies ameaçadas.

ISSN: $2236-2886$ 